\title{
EDITORIAL
}

\section{WHITHER PHYSIOTHERAPY?}

From recent reports in the medical and physiotherapy literature, it is clear that the profession has reached a cross roads. Crucial decisions have to be taken about the training of future physiotherapists in order to determine the direction the profession will take in the future (Wyke, 1980). A wide spectrum of practice alleady exists in some countries. In the traditional model all patients are referred to the physiotherapist by the medical practitioner, often with very precise injtructions as to the physiotherapy to be administered, relegating physiotherapists to the level of technicians. However, a new breed of physiotherapists, acting as independent professional consultants in their own right, have developed. This has engendered feelings of threat in medical practitioners who feel that "colleagues, yalued for their skills, respected for their own training, re increasingly transgressing the sacred clinical bounGary between doctor and patient" (Pearce, 1980). He feels that allowing paramedicals to be directly involved in determining a patient's treatment is as unsound as it is frankly dangerous and wonders who is responsible and answerable in law, should things go wrong,

In a study conducted to explore the physiotherapist/ doctor relationship in two aspects, viz. the performance of doctors as team leaders, consultants and resource personnel; and the physiotherapist's desire to interact with doctors and medical students, some interesting findings came to light (Ross et al., 1980). The doctors acuse the physiotherapists of a "drive for independence, away from medicine and the medical model". The physiotherapists on the other hand felt that the doctors were not performing well as team leaders and that there was a breakdown in the multidisciplinary team and communication, in both directions. The team leader should delegate and leave individual team members autonomy and authority over details. As doctors receive very little instruction in physiotherapy, it was felt they are qualified only to give a diagnosis and desired outcome of therapy when referring patients. It would seem reasonable that the physiotherapist should decide on the modality of treatment after being given full information about the aims of treatment and likely outcome, drugs being administered and disease characteristics. After all, treatment should be geared at the individual. The investigators concluded that physiotherapists wished to be members of the team but that it is the proper place of the physiotherapist and doctor in the medical team that is controversial.

In the midst of all this controversy, the patient, who is most concerned as the consumer, appears to have no say. Physiotherapists and doctors alike should learn to listen to the patient and communicate with him in a meaningful way. The doctor/patient relationship is often seen as a symbol of the doctor's independence and interference is professionally threatening. Doctors feel that only they should diagnose as it is safer and the proper role of the doctor (Bowling, 1980). However, as much as patients needs doctors, doctors also need patients with problems to solve.

The explosion of new knowledge in areas such as biophysics and neurology will undoubtedly lead to improved understanding of physiotherapy techniques and result in more effective skills developing, but it would be a pity if the art of physiotherapy is lost in the process. There seems to be a need to develop a more consumer-centred health service, where the patient and his needs are the most important considerations. Until this happens, the anxieties of the various professional pressure groups may take precedence and impair and delay the development of a really caring healthcare system.

\section{Refierences}

Bowling, A. (1980). Who is afraid of the paramedic? World Medicine 15, (June) 48.

Pearce, J. (1980). Whose patient is it anyway? World Medicine 15, (February) 70.

Ross, C. A., Roberts, L. W., Olson, L. (1980). The. doctor-physiotherapist relationship: the physiotherapists perspective. Physiother. Canada 32, 219-223. Wyk, B. (1980). Perspectives in physiotherapy. Physiother. Canada 32, 261 - 267.

\section{Contents - Inhoud}

Wither Physiotherapy? - Editorial ... ... ...

P.U.V.A.-Photochemotherapy of Psoriasis with Oral 8-Methoxypsoralen and Long Wave Ultra Violet Radiation

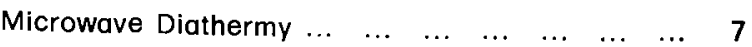

The Thermal Effects of Pulsed Ultrasound ... ... 10
Temperature Changes Induced by Continuous

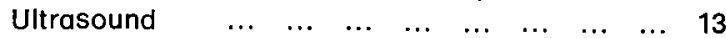

Medical Officers' Attitudes Towards Physiotherapy 15 The Role of Physical Education and Sport in a Cecrebral Palsy School and the Interaction of Therapists and Physical Educationists $\ldots$... 17 Classified - Vacancies $\ldots$. 